\title{
Análise de performance dos protocolos WRP, ZRP, AODV e DSR em ambiente móvel sem fio com a implementação de um sistema de cache
}

\author{
Demóstenes Zegarra Rodríguez, André Luis Pereira Correa e Miguel Arjona Ramírez
}

\begin{abstract}
Resumo-Com a utilização crescente de dispositivos móveis em ambientes wireless há a necessidade de se implementar novas soluções associadas aos protocolos de roteamento para benefício das comunicações entre usuários. Este trabalho faz a análise dos protocolos pró-ativos (WRP), reativos (AODV e DSR) e híbrido (ZRP) em um cenário sem fio móvel (MANET) e propõe um mecanismo de cache para melhora dos parâmetros como perda de pacotes, vazão e latência. Como os protocolos AODV e WRP apresentaram uma menor perda de pacotes e uma maior vazão em comparação com os demais protocolos, o mecanismo de cache foi implementado somente nestes dois protocolos causando um aumento da vazão e uma diminuição da perda de pacotes de 16 a $45 \%$ após a aplicação do sistema de cache no protocolo WRP, sendo que a diminuição de perda de pacotes ocorreu, principalmente, nos cenários móveis, que possuem várias aplicações como, por exemplo, nas redes sensores.
\end{abstract}

Palavras-Chave-protocolo de roteamento, MANET, AODV, DSR, WRP, ZRP.

Abstract - With the increasing use of mobile devices in wireless environments there is a need to implement new solutions related to routing protocols for the benefit of communications between users. This work does the analysis of pro-active protocols (WRP), reactive (AODV and DSR) and hybrid protocols (ZRP) in a wireless mobile scenario (MANET), and proposes a mechanism for improvement of cache parameters under loss of packets, throughput and latency. As protocols AODV and WRP showed lower packets loss and higher throughput in comparation with the other protocols without the implementation of the cache, this mechanism is recommended only for these protocols causing an increase in throughput and decrease the loss of packets of 16 to $45 \%$ after the application of the cache system in the protocol WRP, and the reduction of loss of packets occurred, mainly in mobile scenarios, that have various applications such as sensor networks.

Keywords - routing protocol, MANET, AODV, DSR, WRP, ZRP.

\section{INTRODUÇÃO}

Nos últimos anos vem ocorrendo o crescimento do uso de dispositivos móveis sem fio. Com este crescimento a possibilidade de troca de informações entre os vários dispositivos se

Demóstenes Zegarra Rodríguez e Miguel Arjona Ramírez, Laboratório de Processamento de Sinais, Escola Politécnica, Universidade de São Paulo, São Paulo, Brasil e André Luis Pereira Correa, Instituto Nokia de Tecnologia, Manaus, Brasil, E-mails: demostenes.rodriguez@indt.org.br, andre.1.correa@indt.org.br e miguel@1ps.usp.br. Este trabalho recebeu apoio da Fundação de Amparo à Pesquisa do Estado de São Paulo (FAPESP) pelo Proc. 2007/08288-2, do Conselho Nacional de Desenvolvimento Científico e Tecnológico (CNPq) pelo Processo 309249/2008-2 e do Instituto Nokia de Tecnologia. vê útil, pois a capacidade de comunicação deve estar sempre presente. Há então o surgimento das redes Ad Hoc.

Redes Móveis Ad Hoc (MANET) são redes formadas por nós móveis que não dispõem de uma infra-estrutura pré-existente, ou seja, não há a presença de pontos de acesso que auxiliem na comunicação entre os nós.

Os pontos de acesso estão presentes nas redes infraestruturadas, que possuem um funcionamento similar à rede de telefonia celular, onde toda a comunicação deve, necessariamente, passar pela central, mesmo que os equipamentos móveis estejam a uma distância em que poderiam, eventualmente, comunicar-se diretamente. Portanto, uma rede MANET deve possuir características para que o aumento da perda de pacotes, latência e diminuição da vazão não interfiram na boa comunicação entre os nós da rede. Para isso, os protocolos de roteamento de uma rede ad hoc móvel têm uma função importante no gerenciamento desta comunicação.

Alguns trabalhos sobre protocolos de roteamento ad hoc [1], [2], [3] e [4] têm sido propostos. Porém, em determinados momentos em que a mobilidade aumenta, há um comprometimento da entrega de pacotes, conseqüentemente diminuindo a vazão da rede.

O trabalho [5] propõe um mecanismo de Quorum, sistema de replicação de dados, que pode ser benéfico na diminuição da perda de pacotes. Assim, este artigo utilizará um mecanismo similar de armazenamento de dados denominado de sistema de cache, porém se diferencia por abordar não somente o protocolo de roteamento AODV (Ad-Hoc OnDemand Distance Vector) e DSR (Dynamic Source Routing), definidos como protocolos reativos, como também o protocolo pró-ativo WRP (Wireless Routing Protocol) e o protocolo híbrido ZRP (Zone Routing Protocol, pois pesquisas como [6] demonstram que com a variação de tráfego CBR (Constant Bit Rate), o WRP possui uma melhor desempenho nos quesitos atraso e perda de pacotes, indicando que o WRP pode ser fortemente indicado em tráfegos de tempo real, como é o caso de transmissão de voz sobre redes IP. Portanto, neste trabalho implementou-se um sistema de cache nos protocolos de roteamento AODV e WRP.

Este trabalho simula o protocolo de roteamento ZRP para fins de comparação com os demais protocolos.

\section{Protocolos de Roteamento}

Existem diferenças entre os protocolos de roteamento utilizados em redes cabeadas e redes ad hoc devidas a topologia 
altamente variável, seleção de roteadores e demais características fundamentais na determinação do melhor caminho para a entrega de pacotes.

A Figura 1 apresenta os vários tipos de protocolos de roteamento ad hoc existentes atualmente.

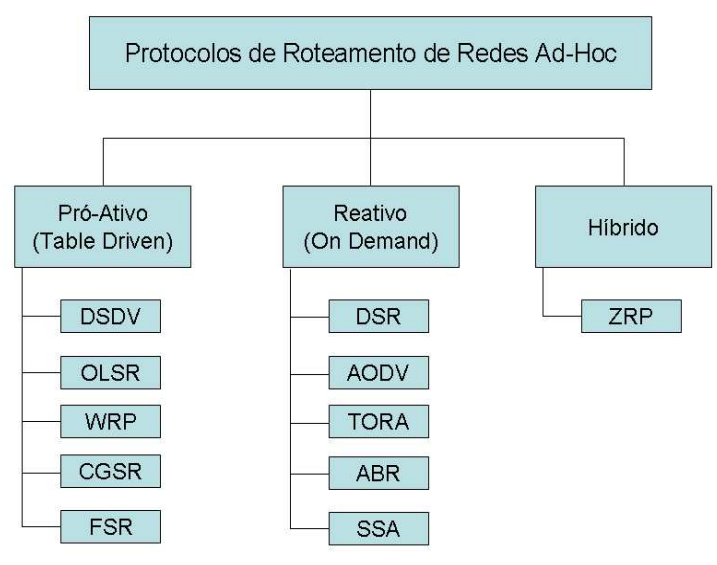

Fig. 1. Tipos de protocolos de roteamento das Redes Ad-Hoc.

Onde:

- DSDV (Destination-Sequenced Distance Vector);

- OLSR (Optimized Link State Routing);

- WRP (Wireless Routing Protocol)

- CGSR (Cluster Gateway Switch Routing);

- FSR (Fisheye State Routing);

- DSR (Dynamic Source Routing);

- AODV (Ad Hoc On-Demand Distance Vector);

- TORA (Temporally Ordered Routing Algorithm);

- ABR (Associativity Based Routing);

- SSA (Signal Stability-Based Adaptive Routing Protocol);

- ZRP (Zone Routing Protocol).

Neste trabalho serão analisados apenas alguns dos principais protocolos de roteamento para redes ad hoc.

Nos protocolos de roteamento pró-ativos (table-driven), os nós da rede mantêm informações de roteamento para todos os nós da rede, de forma que, quando for necessário enviar dados para um determinado nó, a rota para este nó será conhecida.

Exemplo deste protocolo é o WRP [7].

\section{A. Wireless Routing Protocol (WRP)}

Este protocolo pró-ativo em cada nó mantém quatro tabelas: Tabela de Distância, Tabela de Roteamento, Tabela de Custo de Enlace e a Tabela de Lista de Retransmissão de Mensagem (MRL). Os nós informam-se sobre mudanças de enlaces através de mensagens de atualização. Estas mensagens são trocadas somente entre vizinhos e contêm as atualizações, e uma lista indicando quais nós devem reconhecer as atualizações. A MRL guarda que versões de uma mensagem de atualização que precisam ser retransmitidas e que vizinhos devem reconhecer a retransmissão. Se há a queda de um enlace entre dois nós, eles a notificam a seus vizinhos, que modificam suas tabelas de distância e procuram novos caminhos para outros nós. Quaisquer novos caminhos são enviados de volta para os nós originais para que eles atualizem suas tabelas. Os nós aprendem sobre a existência de seus vizinhos através de reconhecimentos e outras mensagens. Se um nó não estiver enviando mensagens, ele deve enviar periodicamente um hello para assegurar a conectividade.

Nos protocolos de roteamento reativos ou por demanda, os nós da rede somente iniciam o processo de descobrimento de rotas no momento em que existe alguma informação a ser transmitida, ou seja, quando há uma demanda. Os protocolos DSR (Dynamic Source Routing) [8] e AODV (Ad-hoc Ondemand Distance Vector) [9] são exemplos de protocolos reativos.

\section{B. Ad Hoc On-Demand Distance Vector (AODV)}

O Protocolo AODV é um protocolo de roteamento reativo de vetor de distância. Ele permite que os dispositivos móveis obtenham rapidamente rotas para novos destinos e não exige que eles mantenham rotas para destinos que não estão em comunicação ativa. Quando há uma necessidade de comunicação entre dois pontos, o nó solicitante envia uma mensagem de Requisição de Rota (Route Request - RREQ) por broadcast a todos os nós vizinhos da rede e, se nenhum destes for o nó destino, estes repassam a mensagem à frente continuadamente até chegar ao nó destino. Este, por sua vez, ao responder a uma RREQ, envia pelo caminho reverso uma mensagem RREP (Route Reply) ao nó fonte. Caso haja alguma falha no enlace que esteja sendo utilizado, causada, por exemplo, pela movimentação de um nó, uma mensagem de erro (Route Error - RERR), avisando sobre a queda do enlace, é enviada a todos os nós afetados.

\section{Dynamic Source Routing (DSR)}

O DSR utiliza as mesmas mensagens do protocolo AODV, possuindo um funcionamento similar a este, com a diferença de que no DSR é usado um cache de rota que armazena todas as informações possíveis extraídas da rota fonte contida em um pacote de dados. No AODV somente a rota mais atual é armazenada, sendo as demais descartadas. Projetado para consumir menos largura de banda, devido à eliminação de mensagens periódicas sobre o estado da rede para efeitos de atualização da sua tabela de rota, esse protocolo se diferencia dos demais, on-demand, pelo fato de os nós não precisarem transmitir mensagens hello periódicas com o propósito de notificar os vizinhos quando estão ativos. Os protocolos AODV e DSR possuem algumas diferenças entre si, como o fato de o DSR trabalhar com um número máximo de até 200 nós.

Protocolos híbridos reúnem em um único protocolo as abordagens de protocolos reativos e pró-ativos. O protocolo ZRP (Zone Routing Protocol) [10] é classificado como protocolo híbrido.

\section{Zone Routing Protocol (ZRP)}

O ZRP funciona como um protocolo híbrido, ou seja, parte do protocolo funciona como um protocolo pró-ativo e outra 
parte como um protocolo reativo. O ZRP tem como princípio que mensagens sejam enviadas periodicamente para se manter o roteamento local, possuindo um mecanismo de prevenção de loops no roteamento através de um número de sequiência e do endereço de origem. A métrica utilizada para limitar o uso da abordagem pró-ativa é a quantidade de saltos, criando uma zona de roteamento (routing zone). Ou seja, as rotas para os nós que estejam dentro da zona de roteamento estarão sempre disponíveis. Em [10] denomina-se essa métrica de zone radius.

\section{SistemA DE Cache}

O sistema de cache implementado neste trabalho foi baseado no sistema de Quorum [5], que se trata de uma ferramenta usada para replicação de dados. Este conjunto de servidores que se divide em Quorum compartilha os dados alocados nele para os demais nós, guardando uma cópia dos dados que trafegam na rede e criando um repositório de dados que neste trabalho será chamado de cache. Portanto, se algum pacote de dados é perdido, os nós da rede recorrem ao sistema de cache, que se trata do repositório de dados formado pelos Quoruns.

A Figura 2 mostra o sistema de cache implementado onde os servidores escolhidos para manterem o repositório de dados estão em preto e os demais nós clientes que fazem uso do sistema de cache estão em branco.

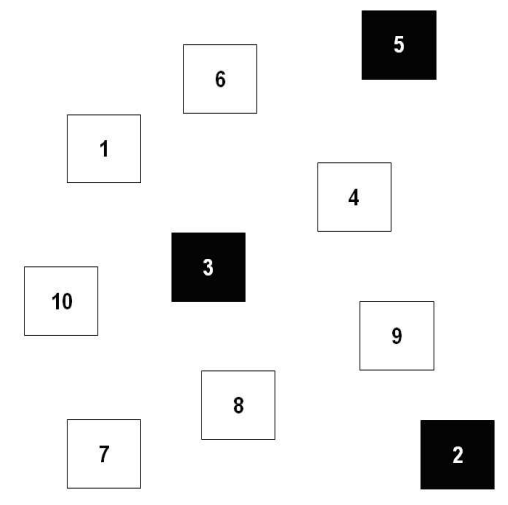

Fig. 2. Sistema de cache em uma rede Ad-Hoc.

Os nós servidores de dados são fixos e são considerados como super nós, ou seja, são nós que possuem um poder de processamento maior que os nós clientes.

Um sistema de cache pode ser utilizado como um backup de dados ou aplicações de segurança de dados compartilhando chaves de segurança.

\section{CenÁrio de Simulação}

No cenário de simulação foi utilizado o simulador Glomosim 2.03 [11]. O simulador é utilizado em várias pesquisas [6], [7] e [12], sendo adequado para ambientes sem fio.

Definiu-se o cenário de simulação como sendo:

- área de: 1000 m x 1000 m;

- tempo de simulação: 5 minutos;

- número de nós: 80;
- tráfego de dados: um conjunto de 30 fluxos CBR entre pares de nós aleatoriamente selecionados. A taxa de transmissão é de 1 pacote a cada 0,5 segundos; cada pacote contendo 160 bytes;

- mobilidade: cenário sem mobilidade e os demais com mobilidade com período de pausa de 50, 100, 150, 200 e 250 segundos.

Foram feitas simulações com os protocolos:

- AODV;

- DSR;

- WRP;

- ZRP com zone radius $=2$.

Os parâmetros medidos nas simulações realizadas são os seguintes:

- Vazão (bit/s): parâmetro que indica os dados transmitidos efetivamente em uma unidade de tempo.

- Latência (s): representa o tempo gasto por um pacote do nó fonte ao nó destino.

- Perda de pacotes (\%): representa a razão da diferença entre o número de pacotes enviados e recebidos para o número de pacotes enviados, em valores percentuais.

- Consumo de Energia (mWh): é a soma total da energia consumida pelos nós durante a simulação.

\section{RESUltados}

Foram feitas 50 simulações de cada protocolo de roteamento para obtenção de um resultado médio válido. $\mathrm{O}$ desvio padrão obtido foi em torno de $0,12 \mathrm{mWh}$ para consumo de energia, 0,03 s para latência, 0,76\% para perda de pacotes e 327 bit/s para vazão em um total de $76,8 \mathrm{kbit} / \mathrm{s}(30 \mathrm{x}$ [2 pacotes $/ \mathrm{s} \times$ 160 Byte/pacote x 8 bit/byte]).

A Figura 3 mostra um menor consumo de energia do AODV e DSR porque estes protocolos são reativos, fazendo requisições de rotas somente quando existe informação a ser transmitida e não periodicamente, mesmo que não haja dados na rede a ser transmitidos, como nos casos em que ocorrem mudanças de enlaces e mensagens de atualização entre os nós devem ser trocadas como ocorre nas redes pró-ativas.

Na Figura 3 o tempo de 300 segundos representa o cenário sem mobilidade.

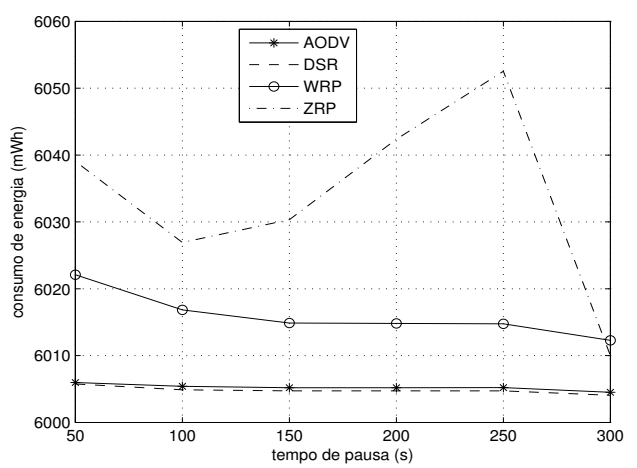

Fig. 3. Consumo de energia ( $\mathrm{mWh}$ ) dos protocolos de roteamento (AODV, DSR, WRP e ZRP) sem a aplicação do sistema de cache. 
Porém, a diferença de consumo de energia entre os protocolos de roteamento não é significativa.

A Figura 4 mostra uma vazão constante do AODV que se mostra útil tanto nos cenários móveis como nos sem mobilidade. Nota-se porém, que o ZRP possui uma vazão baixa nos cenários móveis, pois é baseado em zonas de roteamento definidas a partir de cada nó. No ZRP, para cada nó é exigido que se conheça apenas as informações referentes à sua zona de roteamento.

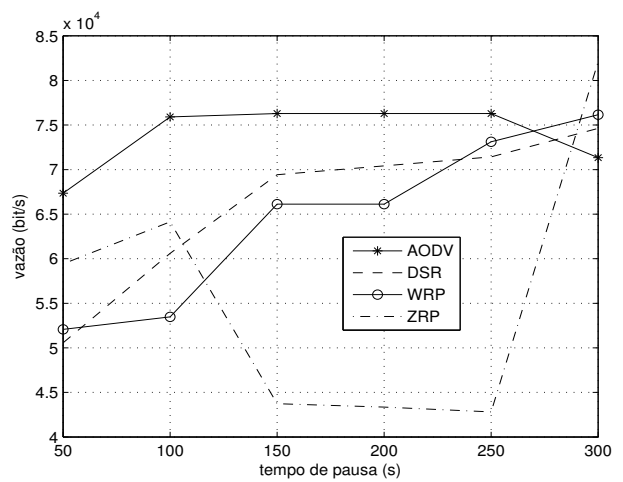

Fig. 4. Vazão (bit/s) dos protocolos de roteamento (AODV, DSR, WRP e ZRP) sem a aplicação do sistema de cache.

Pelo fato de este protocolo híbrido possuir uma visão parcial da rede em mobilidade, as rotas devem ser refeitas rapidamente, o que não ocorre diminuindo a vazão e conseqüentemente aumentando a perda de pacotes como pode ser observado na Figura 5. Os protocolos AODV, WRP e DSR possuem uma desempenho similar.

A perda de pacotes é maior nos cenários com mobilidade, ou seja, com períodos de pausa iguais a 50,100, 150, $200 \mathrm{e}$ 250 segundos, conforme pode ser visto na Figura 5.

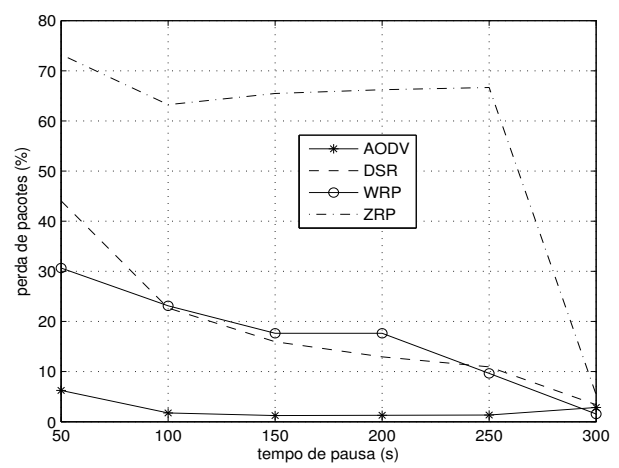

Fig. 5. Perda de pacotes $(\%)$ dos protocolos de roteamento (AODV, DSR, WRP e ZRP) sem a aplicação do sistema de cache.

A Figura 6 mostra uma latência muito parecida entre os protocolos de roteamento empregados, com exceção do ZRP que, ao recalcular as rotas entre seus vizinhos, adiciona à rede uma determinada latência.

As Figuras 7 e 8 apresentam as soluções de cache implementadas sobre os protocolos de roteamento AODV e WRP.

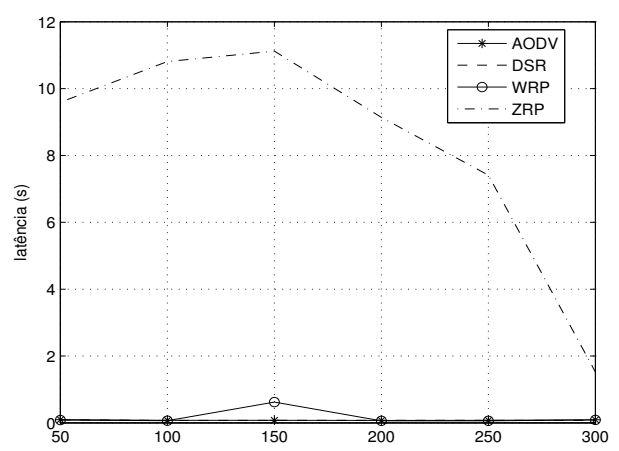

Fig. 6. Latência (s) dos protocolos de roteamento (AODV, DSR, WRP e ZRP) sem a aplicação do sistema de cache.

Estes dois protocolos foram selecionados por terem um melhor desempenho nos cenários sem sistema de cache.

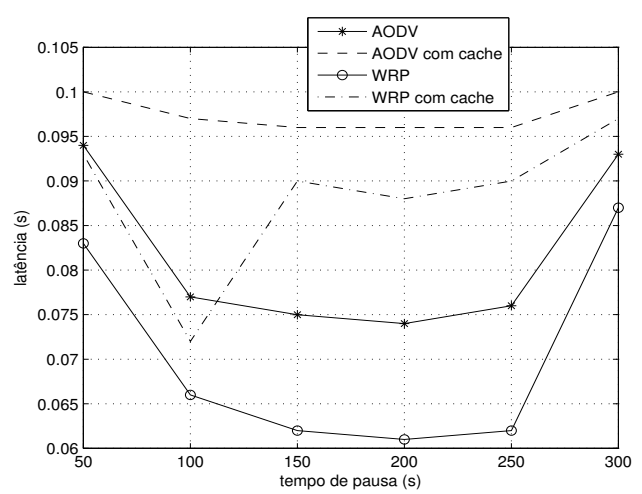

Fig. 7. Latência (s) dos protocolos de roteamento AODV e WRP com e sem a aplicação do sistema de cache.

A Figura 8 mostra que, ao se adicionar o sistema de cache, há uma pequena diminuição de perda de pacotes no protocolo AODV ao passo que no protocolo WRP há uma diminuição significativa de 16 a $45 \%$. Este sistema é mais eficiente com o WRP pelo fato deste ser mais sensível à mobilidade e o sistema de cache auxiliar na diminuição de perda de pacotes em mobilidade, pois se uma informação é perdida os nós podem recorrer aos nós servidores de dados que implementam o sistema de cache, que possuem os dados replicados disponíveis para os nós não servidores de dados. Porém, ao diminuir a perda de pacotes há um acréscimo da latência, Figura 7, pois, quando um nó procura por um dado replicado no sistema de cache, há um atraso causado pelo tempo de busca e recuperação da informação.

Ocorrendo a diminuição da perda de pacotes, consequentemente há um aumento da vazão de dados no caso do protocolo WRP. O consumo de energia não apresenta nenhum benefício com a aplicação do sistema de cache.

As Tabelas I e II apresentam os valores médios e desvios padrões para a perda de pacotes (\%) do AODV com e sem cache e do WRP com e sem cache, respectivamente.

A Tabela I mostra que o protocolo de roteamento AODV não é tão sensível à mobilidade como o protocolo WRP, 


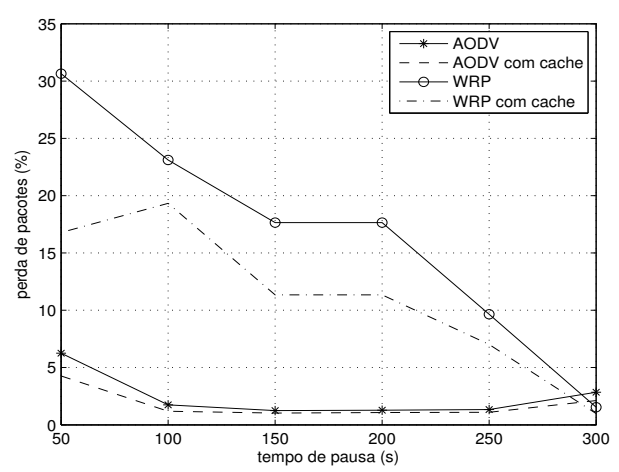

Fig. 8. Perda de pacotes (\%) do AODV e WRP com e sem a aplicação do sistema de cache.

pois a maior variação ocorre no cenário de 50 segundos de período de pausa, sendo que nos demais os valores de perda de pacotes são semelhantes. Porém, mesmo assim nota-se um benefício da aplicação do sistema de cache em torno dos $31 \%$ de diminuição de perda de pacotes nos cenários de maior mobilidade, períodos de pausa de 50 e 100 segundos e de $16 \%$ nos cenários com menor mobilidade.

TABELA I

VALORES MÉdIOS E DESVIOS PADRÕES PARA A PERDA DE PACOTES (\%) DO AODV COM E SEM cache.

\begin{tabular}{|c||c|c|}
\hline & Pausa $(\mathrm{s})$ & Perda de pacotes (\%) \\
\hline \hline AODV & 50 & $6,25 \pm 0,46$ \\
\hline AODV & 100 & $1,74 \pm 0,71$ \\
\hline AODV & 150 & $1,24 \pm 0,70$ \\
\hline AODV & 200 & $1,28 \pm 0,65$ \\
\hline AODV & 250 & $1,34 \pm 0,73$ \\
\hline AODV & 300 & $2,85 \pm 0,55$ \\
\hline AODV + cache & 50 & $4,26 \pm 0,51$ \\
\hline AODV + cache & 100 & $1,19 \pm 0,71$ \\
\hline AODV + cache & 150 & $1,03 \pm 0,76$ \\
\hline AODV + cache & 200 & $1,07 \pm 0,49$ \\
\hline AODV + cache & 250 & $1,10 \pm 0,48$ \\
\hline AODV + cache & 300 & $2,12 \pm 0,60$ \\
\hline
\end{tabular}

TABELA II

VALORES MÉDIOS E DESVIOS PADRÕES PARA A PERDA DE PACOTES (\%) DO WRP COM E SEM cache.

\begin{tabular}{|c||c|c|}
\hline & Pausa (s) & Perda de pacotes (\%) \\
\hline \hline WRP & 50 & $30,64 \pm 0,64$ \\
\hline WRP & 100 & $23,11 \pm 0,69$ \\
\hline WRP & 150 & $17,65 \pm 0,64$ \\
\hline WRP & 200 & $17,65 \pm 0,71$ \\
\hline WRP & 250 & $9,65 \pm 0,73$ \\
\hline WRP & 300 & $1,54 \pm 0,50$ \\
\hline WRP + cache & 50 & $16,78 \pm 0,68$ \\
\hline WRP + cache & 100 & $19,33 \pm 0,60$ \\
\hline WRP + cache & 150 & $11,34 \pm 0,69$ \\
\hline WRP + cache & 200 & $11,34 \pm 0,70$ \\
\hline WRP + cache & 250 & $7,02 \pm 0,68$ \\
\hline WRP + cache & 300 & $0,98 \pm 0,70$ \\
\hline
\end{tabular}

A Tabela II mostra que o WRP possui uma perda de pacotes considerável nos cenários móveis e no sem mobilidade, sendo que o cenário com período de pausa de 300 segundos é representado como o cenário sem mobilidade. Com a aplicação do sistema de cache há uma diminuição da perda de pacotes de $45 \%$ no cenário com período de pausa de 50 segundos, cenário este de maior mobilidade e em torno de 20 a $30 \%$ nos demais cenários.

\section{CONCLUSÕES}

Este trabalho demonstra que em cenários em que a diminuição da perda de pacotes é essencial, a solução proposta é benéfica, propiciando, no caso principalmente do protocolo WRP, uma diminuição na perda de pacotes de até $45 \%$ no cenários com maior mobilidade e conseqüentemente um aumento da vazão de dados na rede. Esta diminuição da perda de pacotes será especialmente benéfica em aplicações em tempo real, como, por exemplo, em comunicações de voz sobre IP, melhorando a qualidade desta.

Como uma rede ad hoc móvel exige que as rotas entre os nós devem estar sempre atualizadas e isso é um fator crítico nesses tipos de rede, o parâmetro de perda de pacotes acaba sendo, normalmente, sacrificado, de forma que o sistema de cache apresentado neste trabalho se mostra útil e válido nesse tipo de cenário.

Trabalhos futuros sobre como o sistema de cache poderia diminuir sua interefência no parâmetro de latência serão efetuados.

\section{AgRAdecimentos}

Os autores agradecem o Laboratório de Processamento de Sinais da Universidade de São Paulo e o Laboratório de Telecomunicações do Instituto Nokia de Tecnologia pela motivação à pesquisa na área de Sistemas de Telecomunicações.

\section{REFERÊNCIAS}

[1] Perkins C., Bhagwat P., Highly Dynamic Destination Sequenced Distance Vector Routing for Mobile Computers. Proceedings of the SIGCOMM '94 Conference on Communication Architectures, Protocols and Applications 1994; 234244.

[2] Perkins C.,Royer EM., Ad hoc On Demand Distance Vector (AODV) Routing. Proceedings of the Second IEEE Workshop on Mobile Computing Systems and Applications 1999; 90100.

[3] Johnson DB., Maltz DA., Dynamic Source Routing in Ad Hoc Wireless Networking, Mobile Computing; Kluwer Academic Publishing: New York, 1996.

[4] Corson MS., Ephremides A., A Distributed Routing Algorithm for Mobile Wireless Networks. ACM Baltzer Wireless Networks Journal 1995; 1(1):6181.

[5] Rosa, R.; Amazonas, J., Gossip-Quorum-AODV Based Fault Tolerant Ad-Hoc Networks. In: International Workshop on Telecommunications, 2009, São Paulo. Proceedings of the International Workshop on Telecommunications, 2009.

[6] Study of MANET routing protocols by GloMoSim simulator. International Journal of Network Management. vol. 15 , no. 6, November 2005, pp. $393-410$.

[7] Murthy S., Gracia Luna Aceves JJ., An Efficient Routing Protocol for Wireless Networks. ACM Mobile Networks and Applications Journal, Special Issue on Routing in Mobile Communications Networks 1996; 183197.

[8] Johnson, D., Maltz, D. Dynamic Source Routing in Ad Hoc Wireless Networks. Mobile Computing. (1996), pp.153-181.

[9] Perkins C., Royer EM., Ad hoc On Demand Distance Vector (AODV) Routing. Proceedings of the Second IEEE Workshop on Mobile Computing Systems and Applications. 1999; 90100. 
XXVII SIMPÓSIO BRASILEIRO DE TELECOMUNICAÇÕES - SBrT 2009, DE 29 DE SETEMBRO A 2 DE OUTUBRO DE 2009, BLUMENAU, SC

[10] Haas, Z., A New Routing Protocol for the Reconfigurable Wireless Networks. IEEE ICUPC. Vol 2, No. 1, Outubro, 1997, pp. 562-566.

[11] Glomosim - Global Mobile Information System Simulation Library, http://pcl.cs.ucla.edu/projects/glomosim.

[12] Z.J. Haas, J.Y. Halpern, L. Li, Gossip-based ad hoc routing Networking, IEEE/ACM Transactions on Volume 14, no. 3, June 2006, pp 479 - 491. 